\title{
Uusioersily
}

\section{Emerging trends in the novel drug delivery approaches for the treatment of lung cancer}

Tambuwala, M. M. (2019). Emerging trends in the novel drug delivery approaches for the treatment of lung cancer. Chemico-Biological Interactions, 309, [108720]. https://doi.org/10.1016/j.cbi.2019.06.033

Link to publication record in Ulster University Research Portal

\section{Published in:}

Chemico-Biological Interactions

Publication Status:

Published (in print/issue): 25/08/2019

DOI:

10.1016/j.cbi.2019.06.033

\section{Document Version}

Author Accepted version

\section{General rights}

Copyright for the publications made accessible via Ulster University's Research Portal is retained by the author(s) and / or other copyright owners and it is a condition of accessing these publications that users recognise and abide by the legal requirements associated with these rights.

\section{Take down policy}

The Research Portal is Ulster University's institutional repository that provides access to Ulster's research outputs. Every effort has been made to ensure that content in the Research Portal does not infringe any person's rights, or applicable UK laws. If you discover content in the Research Portal that you believe breaches copyright or violates any law, please contact pure-support@ulster.ac.uk. 


\section{Accepted Manuscript}

Emerging trends in the novel drug delivery approaches for the treatment of lung cancer

Parvarish Sharma, Meenu Mehta, Daljeet Singh Dhanjal, Simran Kaur, Gaurav Gupta, Harjeet Singh, Lakshmi Thangavelu, S. Rajesh Kumar, Murtaza Tambuwala,

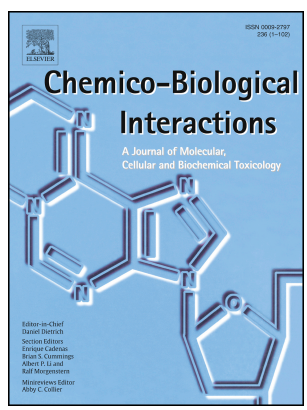
Hamid A. Bakshi, Dinesh Kumar Chellappan, Kamal Dua, Saurabh Satija

PII: S0009-2797(19)30765-3

DOI: https://doi.org/10.1016/j.cbi.2019.06.033

Reference: $\quad$ CBI 8720

To appear in: Chemico-Biological Interactions

Received Date: 6 May 2019

Revised Date: 1 June 2019

Accepted Date: 17 June 2019

Please cite this article as: P. Sharma, M. Mehta, D.S. Dhanjal, S. Kaur, G. Gupta, H. Singh, L. Thangavelu, S.R. Kumar, M. Tambuwala, H.A. Bakshi, D.K. Chellappan, K. Dua, S. Satija, Emerging trends in the novel drug delivery approaches for the treatment of lung cancer, Chemico-Biological Interactions (2019), doi: https://doi.org/10.1016/j.cbi.2019.06.033.

This is a PDF file of an unedited manuscript that has been accepted for publication. As a service to our customers we are providing this early version of the manuscript. The manuscript will undergo copyediting, typesetting, and review of the resulting proof before it is published in its final form. Please note that during the production process errors may be discovered which could affect the content, and all legal disclaimers that apply to the journal pertain. 


\section{Emerging Trends in the Novel Drug Delivery Approaches for the Treatment of Lung} Cancer

Parvarish Sharma $^{1^{*}}$, Meenu Mehta $^{1 *}$, Daljeet Singh Dhanjal ${ }^{2}$, Simran Kaur $^{2}$, Gaurav Gupta ${ }^{3}$, Harjeet Singh ${ }^{4}$, Lakshmi Thangavelu ${ }^{5}$, S. Rajesh Kumar ${ }^{5}$, Murtaza Tambuwala ${ }^{6}$, Hamid A. Bakshi $^{6}$, Dinesh Kumar Chellappan ${ }^{7}$, Kamal Dua $^{8,9,10 \#}$, Saurabh Satija ${ }^{1 \#}$

${ }^{1}$ School of Pharmaceutical Sciences, Lovely Professional University, Phagwara-144411, Punjab, India

${ }^{2}$ School of Bioengineering and Biosciences, Lovely Professional University, Jalandhar-Delhi G.T. Road (NH-1), Phagwara-144411, Punjab, India.

${ }^{3}$ School of Phamacy, Suresh Gyan Vihar University, Jagatpura, Mahal Road, Jaipur,

India ${ }^{4}$ National Medicinal Plants Board, Ministry of AYUSH, New Delhi, India

${ }^{5}$ Savitha Dental College and Hospitals, Saveetha University, SIMATS, Chennai, Tamilnadu,

India

${ }^{6}$ School of Pharmacy and Pharmaceutical Sciences, Ulster University, Coleraine, County

Londonderry, BT52 1SA, Northern Ireland, United Kingdom

${ }^{7}$ Department of Life Sciences, School of Pharmacy, International Medical University, Bukit Jalil 57000, Kuala Lumpur, Malaysia

${ }^{8}$ Discipline of Pharmacy, Graduate School of Health, University of Technology Sydney, Ultimo NSW 2007, Australia

${ }^{9}$ Priority Research Centre for Healthy Lungs, Hunter Medical Research Institute (HMRI) \& School of Biomedical Sciences and Pharmacy, University of Newcastle, Callaghan,

NSW 2308, Australia

${ }^{10}$ Centre for Inflammation, Centenary Institute, Sydney, NSW, 2050, Australia

\section{*First two authors have equal contribution}

\#Corresponding author(s):

Dr. Saurabh Satija, Assistant Professor, School of Pharmaceutical Sciences, Lovely Professional University, Jalandhar-Delhi G.T. Road (NH-1), Phagwara-144411, Punjab, India, E-mail ID: saurabh.21958@1pu.co.in Dr. Kamal Dua, Discipline of Pharmacy, Graduate School of Health, University of Technology Sydney, Ultimo NSW 2007, Australia, E-mail ID: Kamal.Dua@uts.edu.au 


\begin{abstract}
Cancer is one of the major diseases that cause a high number of deaths globally. Of the major types of cancers, lung cancer is known to be the most chronic form of cancer in the world. The conventional management of lung cancer includes different medical interventions like chemotherapy, surgical removal, and radiation therapy. However, this type of approach lacks specificity and also harms the adjacent normal cells. Lately, nanotechnology has emerged as a promising intervention in the management and treatment of lung cancers. Nanotechnology has revolutionized the existing modalities and focuses primarily on reducing toxicity and improving the bioavailability of anticancer drugs to the target tumor cells. Nanocarrier systems are being currently used extensively to exploit and to overcome the obstructions induced by cancers in the lungs. The nano-carrier-loaded therapeutic drug delivery methods have shown promising potential in treating lung cancer as its target is to control the growth of tumor cells. In this review, various modes of nano drug delivery options like liposomes, dendrimers, quantum dots, carbon nanotubes and metallic nanoparticles have been discussed. Nano-carrier drug delivery systems emerge as a promising approach and thus is expected to provide newer and advanced avenues in cancer therapeutics.
\end{abstract}

Keywords: Cancer, Lung cancer, Target drug delivery, Nano-carrier, Nanotechnology 


\section{Introduction}

Cancer remains to be one of the major health problems in both developed and developing countries globally [1]. Hippocrates first introduced the term "cancer" in 370 BC and stated that these are abnormally growing cells due to chromosomal alterations [2]. On an approximate, around 1.6 million cancer cases have been reported in the United States alone each year [3]. There are more than 100 different types of cancers categorised by organ and tissues of origin. Of all these types, lung cancer is the leading cause of deaths, where, chronic smoking is considered to be the major cause, in addition to the other contributing factors. Interestingly, it has been reported that men and women are equally exposed to both direct and indirect smoking [4]. About 1.04 million cases of lung cancer are recorded each year worldwide, with the highest prevalence observed in North America and Europe. According to the available statistical data, the 5-year relative survival rate for patients having lung cancer was a mere $13 \%$ in 1975 , whereas, during 1996 to 2003, it increased to $16 \%$ [5]. Every year, the number of deaths due to lung cancers is far more than the other types of cancers; namely, breast, colorectal or prostate cancer to name a few. In developing countries, the percentage of people having lung cancers is exponentially high, as more than $50 \%$ of cases belong to the local population [6]. Rapid development, urbanization and environmental pollution are the other major contributors, apart from smoking habits, that account towards the increased number of patients suffering from respiratory diseases [7]. Lung cancer is categorised into two categories based on histological assessment, which are; i) Smallcell lung cancer (SCLC) and ii) Non-small cell lung cancer (NSCLC). [8] In developing countries, NSCLC is very common, primarily due to smoking, and it accounts for at least $85 \%$ of cases of lung cancer, whereas, SCLC accounts for the rest of the $15 \%$ cases [9]. NSCLC is further categorized into three sub-categories, i.e., a) Adenocarcinoma (AD), b) Large-cell carcinoma (LC) and Squamous-cell carcinoma (SQ) [10].

Inspite boasting of advanced medical interventions like surgical removal, chemotherapy, and radiation therapy, nevertheless, it has become even more challenging to control the deaths due to lung cancer. These traditional approaches lack precision and deliver minimal amounts of therapeutic drugs (due to their lipophilic nature and high first-pass metabolism). Due to their non-targeting nature, majority of chemotherapeutics act on normal tissues, leading to adverse effects [11]. This gap in medical advancement has led to the exploration and search for newer 
targeted therapeutic approaches. In recent decades, the introduction of nanotechnology has unlocked new prospects for targeted therapeutic delivery and attributed towards the development of nano-based drug delivery systems [12]. These nano-based drug delivery systems deliver anticancer drugs in high concentration to the tumor site and prevent the accumulation of such drugs in normal organs [13]. A number of databases and search engines like Medline, PubMed, HubMed, Clarivate Analytics, Scopus, Science Citation Index (SCI), Indian Citation Index (ICI), American Chemical Society (ACS), SciElo, Science Direct etc. were queried out for scientific findings and accessing the articles in academic journals, institutional repositories, archives or other collection of scientific articles. This review intends to provide an overview and discusses the recent advancements in the field of nanocarrier drug delivery systems for the management of lung cancer.

\subsection{Global prevalence of lung cancer}

Over the past few centuries, the prevalence of lung cancer has shifted from being a rare disease to a common disease worldwide. Lung cancer is the most commonly occurring cancer in men and the third most commonly occurring cancer in women. According to the American Cancer Society (ACS), in 2018 alone, it accounted for 234,030 newly diagnosed cases, representing 14\% of all newly diagnosed cancer cases and 154,050 deaths, which is 1.4 folds higher than as seen in developed countries [14]. In European countries, there were about 75\% death cases among men and about $80 \%$ of death cases among women which have been reported, due to lung cancer. However, the highest mortality among men was recorded in the Central and Eastern Europe regions [15], whereas, the highest mortality among women was recorded in the north-western parts of Europe, in countries namely, Denmark, UK and Netherlands [16].

Considering 'age' as the detrimental factor for lung cancer, the occurrence of lung cancer before 44 is very rare for both sexes. A high percentage of mortality has been reported in African, EastMediterranean and South-East Asia region in the age group of 45 to 62 years. A similar trend has been observed for the middle age group of 54 to 64 years. About $30 \%$ of deaths due to lung cancer is recorded in the age group of 65 to 74 years from all regions [17]. In comparison to the current scenario, it has been predicted that the mortality rate of lung cancer patients may increase from 1.6 million to a staggering 3 million. In addition, it has been predicted that the mortality rate of men may double the mortality rate of women [18] in the next few decades. Globally, it 
has been estimated that more than $50 \%$ of lung cancer deaths occur in the Western Pacific region followed by the Americas, the European and the South-East Asia regions [3].

In contrast, only 1-2\% of deaths, due to lung cancer, are recorded from the African and the EastMediterranean regions. The Western Pacific region will continue to be ranked 1 in terms of mortality due to lung cancer, owing to the high mortality rate [19]. In addition, it is further predicted that the gap between other regions will continue to expand. Assessment of the temporal trend of lung cancer in countries like Argentina, Canada, Chile and the US showed two different scenarios, i.e., a decrease in the mortality rate among men in both the US and Argentina and an increased mortality rate among both men and women in Canada and Chile [18]. A similar scenario was observed on the assessment of European countries. The trend of decreasing mortality rate of men in countries like Australia and New Zealand is predicted to be continued in the future [20]. The similar prediction has been stated for China until 2035 [3]. It has been also predicted that in the next two decades; Japan will experience an exponential increase in lung cancer cases for both sexes [21]. In developing countries like Egypt, India, Indonesia and Saudi Arabia, it has been predicted that the number of death cases due to lung cancer will increase [22][23].

\subsection{Traditional methods and the importance of nano-carriers in the treatment of lung cancer}

Treatment of any cancer aims to remove or destroy the cancerous cells without killing normal cells. The most common traditional methods used for treatment include surgery, radiation, and chemotherapy which can be used either alone or in combination with each other [8][24]. The most consistent and effective option to treat patients suffering from lung cancer is surgical resection. In 1933, the first resection of a tumour from the lung was reported by Graham via pneumonectomy, and in the past two decades, this has been the principal procedure to treat lung cancer [25]. Stage-I lung cancer patients may be incompetent to bear surgery if their health condition is poor. Radiotherapy has provided relief to patients, who were incapable of undergoing surgery, however, the rate of cure is considerably low in comparison to surgical resection [26]. It is well known that radiotherapy causes damage to the surrounding cells, which in turn significantly leads to the loss in the functionality of the lungs. Thus, this approach may not be appropriate for those patients who have a severely compromised pulmonary system [27]. 
The most common side effects of these traditional methods are illustrated in Fig.1. Hence, there is an urgent need to develop newer and advanced treatment modalities that can effectively eliminate tumour cells which are less invasive and harmless to normal cells in comparison to radiotherapy and surgery. One of the new reported approaches to cure, lung cancer is PDT (Photodynamic Therapy). However, this approach is used for early stage lung cancers that affect the central airways, especially, the light and photosensitized tissues. The therapy primarily employs fiber optic bronchoscope and it has been reported to be successful [28]. The concept of PCT (preoperative chemotherapy) came into existence as tumour cells were becoming resistant to anti-cancer drugs due to genetic alteration. As many as 30 clinical trials are reported on this study which has confirmed the feasibility of this approach with a mild expense of postoperative morbidity as well as mortality [29]. As chemotherapy involving anticancer drugs lacks tumour targeting ability, they affect the surrounding normal cells and impose rigorous side-effects in the patients [30].

Targeted-drug delivery approaches have gained immense attention to overcome this problem [31]. Drug carriers can deliver drugs to the lungs, extend its duration time, regulate its therapeutic dose, reduce the complications and chances of the harmful effect of the toxic drug in the patients. This targeted approach delivers the therapeutic drug to the infected region and reduces its distribution to non-target tissues and organs [25]. Nanotechnology encompasses wide-range of nano-scale tools that can be used for therapeutic purposes. Among them, nanocarriers have revolutionized the field of drug delivery [32]. These nano-carriers have been engineered to release and increase the duration time of drug and protect the therapeutic agent from early degradation and removal by phagocytic cells [33]. The respiratory system involving lungs are suitable for targeted drug delivery, as it provides a large surface area, which allows to skip the first stage metabolism and promotes the onset of rapid therapeutic action [34]. Development of colloidal delivery systems like micelles, liposomes and nanoparticles has opened a new perspective in drug delivery. Unique characteristics like small size, large surface area, ability to amend the surface properties are few advantages of nanoparticles which make it different from the other delivery systems [35]. Furthermore, the sustained release characteristics of nanoparticles may further aid in the effectiveness of inhaled chemotherapy by maintaining 
drug concentrations at tumor sites for longer durations [36]. The applications of different types of nanoparticles are discussed in Table 1.

Nanoparticles facilitate a regulated release of therapeutic drugs into the lung tissue, which in turn decreases the dosage frequency and improves the patient's lung compliance [37]. A combination of intravenously injected human natural killer cells and inhaled interleukin-2 had a synergic effect and increased the survival rate in mice with osteosarcoma lung metastases. Furthermore, aerosolized delivery of liposomal interleukin-2 (IL-2) in dogs has been shown to be effective against pulmonary metastases from osteosarcoma [38]. Thus, nano-based delivery systems are an attractive approach to a therapeutic delivery agent to the lung, as it can retain the therapeutic agents for a longer duration in the lungs.

\section{Novel drug delivery systems for treating lung cancer}

There are different novel drug delivery systems that are developed for treating lung cancers [39] as illustrated in Fig. 2. Moreover, these novel drug delivery systems are further sub-divided into three categories as follows:

\subsection{Liposomes}

Liposomes consist of nano-scaled spherical vesicles which allows them to integrate hydrophobic and hydrophilic drugs in an aqueous centre and its outer appearance resembles the biological membrane [40]. Liposomes have several unique features, viz; its non-toxic nature, the ability of its surface to get easily altered by external stimuli, physical stability, high-vascular density and retention time at the target site [41]. The structure of a liposome comprises of cholesterol and phospholipids along with an aqueous core [42]. Phosphatidylethanolamine and phosphatidylcholine are the most commonly used phospholipids [43]. These liposomes are 0.05$5 \mu \mathrm{m}$ diminutive synthetic vesicles. To obtain the desired size liposomes, one needs to follow the standard procedure and use the required constituents which can readily dissolve in aqueous media [44]. 
Synthesized liposomes deliver the therapeutic agents via targeted strategies like active targeting, passive targeting, $\mathrm{pH}$-responsive targeting, magnetic-responsive targeting, stimuli-responsive targeting, and thermo-responsive targeting. Such specific targeting improves the pharmacodynamic and pharmacokinetic profiles, regulates the release of therapeutic agents and reduces the toxicity in comparison to drug solution [45][46]. Active targeting induced by environment stimuli and ligands also show tremendous benefits during targeted drug delivery to tumor cells. Therefore, this approach increases the bioavailability of therapeutic drugs at the target site, decreases the toxic effects and improves the overall therapeutic response [32].

C-liposomes also known as conventional liposomes, are made up of cholesterol and lipids. These liposomes have an additional benefit as they get readily eliminated from the blood with the help of opsonins and reticuloendothelial system. Hence, the results obtained by this approach confirmed the release of the encapsulated drug in the plasma [46].

"Intelligent liposomes" can be used to transcend these hurdles and can be effectively used as a drug delivery system for treating lung cancer [47]. Another name for these liposomes is "smart liposomes", consisting of a bilayer of phospholipids and surface modifiers or other covering molecules. These "smart liposomes" not only target the tumor cells precisely, but also decrease the chances of MDR (Multi-drug resistance) [48]. The progressive liposomal preparations provide the potential of both mitochondrial and $\mathrm{pH}$-sensitive targeting strategies to elicit the apoptosis and obstruct the provision of energy in resistant tumor cells [49]. A different type of long-circulating liposomes, also known as stealth liposomes have recently received immense recognition in the treatment of lung cancers. As it has more residing and circulation time, it enhances the drug delivery at the targeted site as well as improves the interaction between the therapeutic agent and the receptors in the tumor cells [50].

\subsection{Solid lipid nanoparticles}

Solid lipid nanoparticles (SLNs) are a newly emerging surrogate to the traditional colloidal delivery system. SEM (scanning electron microscopy) and TEM (transmission electron microscopy) analysis have revealed the spherical shape of solid-lipid nanoparticles and their size, ranging from $50-1000 \mathrm{~nm}$. The safety profile of SLNs was attributed to their biocompatible lipids that are highly tolerable by the lungs and body [51]. Therefore, they are highly 
recommended for pulmonary drug delivery, either as suspension or dry powder, without inducing inflammation [52]. Solid-lipid nanoparticles contain solid lipid 0.1-30 \% (w/w), which readily gets mixed in the aqueous solution. About $0.5-5 \%$ of surfactants are added to increase the stability of solid-lipid nanoparticles [53]. Solid lipid nanoparticles fall in the category of a nanoparticulate system containing lipids which remains solid at room temperature [54]. These nanoparticles have various advantages like easy modification, biocompatibility with the lipophilic drug, targeted delivery of the therapeutic agents, enhanced drug stability, reduced toxicity and in addition, avoid the first pass effect in comparison to other colloidal carries [55].

It has been noticed that a large surface area of solid-lipid nanoparticles allows loading of a high amount of drug in it. Moreover, it also protects the drug from the environment and increases the bioavailability of drugs [56]. Of all the nano-carrier systems, Solid-lipid nanoparticles have the characteristics of a fat-emulsion carrier, liposomes carrier, and polymeric nanoparticles, which makes them the ideal carries for targeted drug delivery [57]. Generally, lipid nanoparticles are fabricated by natural surfactants and biocompatible lipids [55]. Most commonly used solid lipids for synthesizing solid-lipid nanoparticles are bee wax, cetyl alcohol, cholesterol butyrate, Compritol 888 ATO, Dynasan, and emulsifying wax [58]. Easy alteration of the surface of these nanoparticles by ligands enhances the target efficiency and makes them a valuable activetargeted delivery system [59].

This approach has illustrated the inordinate potential for targeted application (especially intracellular), by altering gene expression and cellular signaling. Currently, fabricated ultra-solid lipid nanoparticles are employed to target the tumor site [60]. These nano-carriers are now used to enhance the bioavailability of anti-tumor drug like doxorubicin, etoposide, and idarubicin [61]. Additionally, solid lipid nanoparticles are also considered to be a suitable carrier for gene therapy [53].

Cationic solid-lipid nanoparticles have exhibited high transfection efficiency for targeted delivery of therapeutic agents to the p53 gene in lung cancer [62]. The novel solid lipid nanoparticles of DCX have been prepared by using trimyristin (high-melting triglyceride). This method increases the concentration of DCX in tumor tissues, whereas, decreases the same in other organs like heart, kidney, liver, and lung. Thus, solid-lipid nanoparticles are prepared using one or more high melting point glycerides, which may enhance the efficiency of this system [63]. 


\subsection{Nanostructured lipid carriers}

There are few limitations of solid lipid nanoparticles like the expulsion of the drug during storage, the formation of crystals under the varied conditions and low payload capacity, which has led to the development of alternative approaches for targeted drug delivery called as nanostructure lipid carriers [55]. This approach is an amalgam of solid and liquid lipids, that exhibits reduced drug expulsion during storage and has high payload capacity [64]. These carriers form an occlusive layer over the surface, that reduces the water loss via trans-epidermal layer [65]. Different nanostructured lipid carriers have been synthesized for anticancer therapy [66].

One of them is transferrin-linked nanostructure lipid carriers, which have been formulated to improve gene delivery to cancer cells and also the effective delivery of paclitaxel. For this, ligand-conjugates with transferrin are developed; then DNA and paclitaxel are loaded on nanostructured lipid carriers. After the loading of nanostructured lipid carriers, ligands conjugated with transferrin are decorated over its surface. Moreover, the transfection efficiency of nanostructure lipid carriers in-vitro and in-vivo has been evaluated in the NSCLC cell line of humans. The results obtained revealed about high anti-tumor activity, low cytotoxicity, and high gene transfection capability in both in-vitro and in-vivo studies. Hence, it can be concluded that the DNA and paclitaxel-loaded and transferrin-decorated nanostructured lipid carriers have potential to co-deliver both gene and therapeutic agents to the targeted site with high efficiency [67].

\subsection{Polymer-based nano-carriers}

\subsubsection{Polymeric nanoparticles}

In the field of nanotechnology, polymeric nanoparticles have emerged as an effective strategy for treating cancers, as their composition and morphology can be changed according to the need [68]. The polymer used for lung cancer treatment includes alginic acid, chitosan, gelatin, polycaprolactone, polylactide-co-glycolide, and polylactic acid. However, on supplementing these polymeric nanoparticles with sulfide bond, it regulates the release of the therapeutic drug [61][69]. Cationic polymers are known for its cellular toxicity and elevated aggregation in lung capillaries because of their non-degradability and poor compatibility [70]. Therefore, regular 
monitoring of toxicity induced by cationic polymers is required, as on interacting with a biosurfactant, they trigger breathlessness.

The biocompatible and biodegradable characteristics of these polymers result in less toxicity and improved bioavailability [71]. The recently developed polymeric nanoparticles have shown improved activity and recognition ability during the delivery of therapeutic agents. More recently, hyaluronan/polyethyleneimine-coated polymeric nanoparticles have been designed for targeted delivery of DCX (Docetaxel) to the CD4 receptor of lung tumor cells [72]. Another study assessed the efficacy of polylactide-tocopheryl polyethylene glycol (1000) succinate based nanocarrier system for the targeted delivery of CZT (Crizotinib) for treating lung cancer [73]. siRNA (small interfering RNA) has always remained as the challenge. Development in the field of nanotechnology will help in developing novel cationic polymer that can silence these siRNA genes in lung cancer. A study conducted in an in-vivo setting demonstrated the silencing of $50 \%$ targeted gene expression on the action of cationic polymers [74]. Another study highlighted the applicability of low-molecular-weight polymeric nanoparticles in silencing the expression of multiple genes of endothelial cells [75].

\subsubsection{Polymeric micelles}

For controlled release and targeted delivery of hydrophobic anti-neoplastic therapeutic agents, polymeric micelles are commonly used. They are considered to be potential nanocarriers, as they are made up of a co-polymer hydrophobic core that allows the payload of the hydrophobic chemotherapeutic agent and hydrophilic shell for a hydrophilic chemotherapeutic agent [76]. Moreover, the hydrophilic shell increases the stability of these polymeric nano-sized micellar structures. The size of the micelles can vary from $20-100 \mathrm{~nm}$, which is applicable for the delivery of hydrophobic therapeutic drugs, accommodating high payload, high drug permeability, long circulation time in blood stream, uniform distribution and deep tumor penetration of the drug [77]. With the development of personalized medicine, polymeric micelles have gained attention for their role in passive targeted therapy for cancer. Modifications to the surface peptides of these polymeric micelles improve their efficiency for precision targeting. For example, a study reported on integrin-associated polymeric micelles that are found to actively target the tumor cells [78]. The major benefit of this approach is, its biodegradable nature for drug delivery systems which can be used for both cancer and ocular drug delivery. 
It has been found that co-encapsulated polymeric micelles containing both paclitaxel and itraconazole significantly decreased the toxicity in NSCLC [79]. Modified polymeric micelles coated by $\alpha$-Conotoxin ImI have emerged as a promising nanocarrier for targeted delivery of docetaxel to $\alpha 7-n A C h R$ gene in A549 (NSCLC) cell line [80].

\subsubsection{Dendrimers}

Dendrimers are synthetic branched polymeric and bifurcated macromolecules, of size ranging from 10-100 $\mathrm{nm}$. Generally, they are globular in shape and have functional groups on their surface which makes them excellent candidates for drug delivery [81]. Dendrimers are synthesized chemically with a regulated polymeric reaction involving electrostatic and hydrophobic interaction [82]. The surface of these nanocarriers can be fine-tuned, and biodegradability can also be improved [83]. These nanocarriers have emerged as a useful tool in cancer therapy because of its symmetrical shape, biocompatibility, easy biodegradability, high payload, and multiple conjugation point that aid in surface modification [84].

The potential of this nanocarrier has been well-reported in the literature [85]. Effective adsorption of peptide conjugated dendrimers has been reported in an athymic mouse model bearing lung cancer that revealed the real potential of this nanocarrier system in treating lung cancer [86]. Moreover, PEGylated dendrimers exhibited promising applications when used as an aerosol-inhaled drug delivery model [87]. Substantial improvement has also been recorded for doxorubicin delivery via dendrimers.

\subsection{Inorganic nanoparticles}

\subsubsection{Magnetic nanoparticles}

This type of nanoparticles gets affected by surrounding magnetic fields and reach the target site in the body either by an active or passive strategy, because of their ligands. The FDA has approved the usage of magnetic nanoparticles along with chemotherapy, which is a giant leap in treating cancers $[88]$.

Magnetic nanoparticles are made up of super paramagnetic material of size $>25 \mathrm{~nm}$. These nanoparticles are either biodegradable or non-biodegradable [89]. Non-biodegradable magnetic nanoparticles are coated with specific material which causes the leaching of the magnetic core 
and facilitates its excretion through the kidneys [90]. When an external magnetic field is applied to these magnetic nanoparticles, they exhibit thermic effects which trigger cellular apoptosis above $42^{\circ} \mathrm{C}$ and direct killing at $45^{\circ} \mathrm{C}$ [91].

Magnetic nanoparticles comprise a magnetic core which is surrounded by a functional coat. The magnetic core is made up of materials like cobalt, gold, iron, and nickel which provide the magnetic properties to the core. On the other hand, the surface coat prevents agglomeration and reduces the interaction of the magnetic core with other particles [92]. This surface/functional coat can either be a ligand or a biologically active therapeutic substance. Nickel is a trace element, which is essential for humans but in excessive amounts induces toxicity in the gastrointestinal and pulmonary systems [93]. Because of the biocompatibility of $\mathrm{Fe}_{3} \mathrm{O}_{4}$, nanoparticles conjugated with iron oxide are most widely used for the treatment of lung cancer. In addition, nanoparticles of $\mathrm{Fe}_{2} \mathrm{O}_{3}$ are also used for cancer therapy [94]. The advantages and disadvantages of magnetic particles are shown in Table 2. A study showed the enhanced cytotoxicity activity of doxorubicin-magnetic nanoparticles because of the paramagnetic nature of doxorubicin and magnetic nature of iron oxide [95].

Magnetic nanoparticles of iron oxide coated with gold conjugated with 225-antibody have been designed to target EGFR (epithelial-growth factor receptor). These nanoparticles have shown DNA damage and cell-cycle revocation in M/G2-phase [103]. Another study reported the toxicity induced by C225-nanoparticles in Non-small-cell lung carcinoma (NSCLC) [104]. It is well known that nanoparticles of smaller sizes get inhaled and get aggregated in the lungs [105]. In order to overcome this problem, nowadays, magnetic nanoparticles are entrapped in microsized particles. D-mannitol and iron-oxide nanoparticles are most commonly used to synthesize magnetic nanocomposite nano-sized particles. This approach prevents the spreading of the therapeutic agents in blood and delivers the drug directly to the target site [106].

Cisplatin, being a hydrophobic drug, needs a special carrier to improve its antitumor activity. Therefore, a functionalized nanoparticle of $\mathrm{Fe}_{3} \mathrm{O}_{4}$ associated with PEG-PLGA copolymer has been developed which shows the improved antitumor activity of cisplatin in lung cancer [96]. It has been found that Iron-oxide nanoparticles conjugated with gold improves the bio-availability of nanocarriers and are considered safe for treating lung cancers [97]. Because of the aggregating 
nature of gold, gadolinium, and platinum at the tumor site, nanoparticles of these elements are also used for radiotherapy as well as other diagnostic purposes [107].

\subsection{Carbon nanotubes}

Carbon nanotubes are hydrophobic-tubular structures made up of carbon atom between $4 \mathrm{~nm}$ to $100 \mathrm{~mm}$ diameter and can vary according to the arrangement of graphene molecules [108]. Intrinsically, these carbon nanotubes are insoluble in any organic solvents or aqueous solutions and toxicity induced by these in a biological fluid is a major challenge that needs to be addressed [109]. Chemical modification improves the biocompatibility, reduces toxicity and transforms them into water-soluble nano-carriers [110]. Carbon nanotubes have a large surface area. The graphene cavity of carbon nanotubes can accommodate high payloads and has distinct mechanical, electron emission and optical properties which make them a candidate of interest. This nanocarrier has high penetration power as it mimics the structure of a fine needle and the functionalized surface is an additional advantage which improves tumor targeting [111].

Cisplatin was the first anti-tumor drug which was conjugated with single-walled carbon nanotubes for targeting the receptors of epidermal growth factor. The results obtained, revealed an improved efficacy against squamous cancer cells that were showing elevated expression of EGFR. In addition, these showed an enhanced activity against head and neck tumor, as compared to passive targeting because of its nano size [112]. Moreover, carbon nanotubes contain several functional sites on their surface, which enable scientists to perform multiple functions with a single nanocarrier [113]. In-vitro and preclinical trials on murine S180 and PC3 cell lines of docetaxel loaded carbon nanotubes have shown effective results in comparison to free docetaxel [114].

Pluronic F127, the non-ionic surfactant has been used to stabilize supramolecular complexes of carbon nanotubes containing doxorubicin. The drug payload capacity was determined by fluorescence spectrophotometry in multi-walled carbon nanotubes. The intensity of doxorubicin fluorescence majorly depends on the concentration of carbon nanotubes [115]. Furthermore, an efficient releasing of carbon nanotubes can be assured through transmission micrograph. Cytotoxic evaluation on MCF-7 cell lines showed high toxicity in comparison to doxorubicin- 
pluronic complexes and plain doxorubicin [116]. Currently, there are various formulations of carbon nanotubes that have been developed with potential outcomes.

\subsection{Quantum dots}

Lately, nanofabrication has enabled researchers to synthesize nano-sized colloidal particles possessing atom-like properties, known as quantum dots (QDs) [117]. These QDs are considered to be a novel approach for treating lung cancers. As the surface modification of these nanoparticles enhance the biocompatibility and solubility, which makes it a superior fluorescent probe in comparison to organic fluorophores [118]. Large absorption spectra, high photo bleaching, and photo stability are few peculiar characteristics of these QDs [119]. QDs show redundant cycles of fluorescence and excitation with a narrow range of emission spectra [120]. Generally, QDs comprise the elements of group II-VI/III-V. Groups II-IV includes elements like cadmium-telluride, cadmium-selenide, zinc-selenide, and zinc sulfide. Whereas, groups III-V include the elements like gallium arsenide, gallium nitride, indium arsenide and indium phosphide [121].

QDs contain a core and a 'cap' or 'shell' along with a coating of polymer as shown in Fig.3. The cap of the QDs guards the core which is made up of metal complexes. Moreover, lipid-coatedQDs showed promising results towards cancerous cells [122]. Thus, QDs are significantly used for biomedical imaging, and for targeting and labelling of biological entities. During in-vivo studies, QDs coated with PEG were not recognized by the reticuloendothelial system increasing their circulation time within the biological system [123]. QDs are also used for biological imaging, cellular and molecular tracing, estimating toxicity profile, in-vitro imaging (multiplexed), molecular labelling as markers, signal transduction and immuno-histochemical detection [124]. The aqueous solubility of QDs can be increased by coating them with polymer and ligand exchange [71][125]. Due to the immense applications of QDs for diagnostic and imaging, now they are also being used for therapeutic benefits.

\section{Pre-clinical and clinical studies}

Presently, there are several nanoparticle based therapeutic approaches that are under pre-clinical and clinical trials waiting for the approval by the FDA (Food and Drug Administration of USA) or EMA (European Medicines Agency of Europe) [126]. Various nanoparticle based formulations have already been approved after clinical trials for treating different cancers. 
Liposomal based nanocarriers encapsulating Doxil (an anti-tumour drug), sold under the name "Abraxane" was the first FDA approved cancer nano-medicine. Several nano-medicines viz; DaunoXome, Marqibo and Myocet were later approved [127]. The DOTAP/ Chol TUSC2 (lipidbased nanoparticles) formulation is under phase I clinical trial which is being studied for treating metastatic lung cancer patients. SLNs is a different class of carrier for targeted drug delivery. The formulation, SLN-carrier p53 was compared with Lipofectin (commercially available drug), in which SLN-carrier p53 was found to be effective and efficient in treating the transfected p53null H1299 lung cancer cells. This study highlights the potential of this approach and motivates for a preclinical and clinical assessment for its usage in chemo/gene therapy as well as in molecular imaging of cancers [62]. Moreover, one of the polymeric nanoformulations "GenexolPM" is being currently assessed for phase II clinical trials in NSCLC patients [128]. With the success of different formulation of NDDS in the commercial and clinical realm, substantial efforts are being taken to exploit the available approved nanomedicines for their therapeutic potential. We have summarised the current studies related to clinical trials on nanoparticle based formulations for lung cancer in Table 3.

\section{Future prospects}

Novel drug delivery systems (NDDS) are developed with a diverse range of applications and have shown promising results in treating diseases with more safety, efficacy and precision. Many of the clinical approaches involving NDDS not only regulates the indented pattern of drug level within the blood, but also aids in targeting the drugs to a specific site or site of action. As a result, it circumvents the dose-associated toxicity and side effects. Despite the various applications and benefits, nanotechnology cannot be termed as flawless. As we are moving from microparticles to nanoparticles; the size decreases and the number of particles as well as the surface area increases. The increased surface area of the nanoparticles results in an augmented chemical reactivity leading to an uncertainty as to how these particles will react under different conditions. The increased chemical reactivity of nanoparticles brings about the production of reactive oxygen species (ROS), which may cause oxidative stress, inflammation, and damage to DNA, proteins and membranes, ultimately leading to toxicity. In the future, nano-toxicological issues are expected to be resolved for effective lung cancer treatment. In lung cancer therapy, 
nanoparticle-based drug delivery system is predicted to overgrow and unlock a new dimension for treating lung cancer. It is believed that extensive research in this field will endeavour new paradigms and replace the traditional dosage approach with NDDS, which will improve the health care delivery system in the near future.

\section{Conclusion}

Nanotechnology beholds infinite potential and innovative applications which are being continuously explored for detecting, diagnosing, imaging and treating different types of cancers. Development in this field has already aided in resolving the issues of traditional medical interventions like non-specific targeting, low therapeutic efficiency, unforeseen side-effects, and drug-resistance. These nanoparticles-based drug delivery systems have become the ideal carrier for cancer treatment as they can be easily modified. Various nano-carriers like liposomes, solidlipid nanoparticles, nanostructured lipid carriers, polymeric nanoparticles, polymeric micelles, dendrimers, magnetic nanoparticles, carbon nanotubes, and quantum dots have been developed and used in combination with different medical interventions for tracking and targeting the infected site as well as deliver the therapeutic agents. Nanoparticles with multiple structures allow alteration of surface for delivering water-insoluble drugs and impart them the ability to surpass the biological barriers and target desired site within the body. This therapeutic approach has developed hope among the patients suffering from cancer and received an overwhelming response because of its ability to site-specific targeting and low toxicity.

\section{References}

[1] G.B. of D.C. Global Burden of Disease Cancer Collaboration, C. Fitzmaurice, D. Dicker, 
A. Pain, H. Hamavid, M. Moradi-Lakeh, M.F. MacIntyre, C. Allen, G. Hansen, R. Woodbrook, C. Wolfe, R.R. Hamadeh, A. Moore, A. Werdecker, B.D. Gessner, B. Te Ao, B. McMahon, C. Karimkhani, C. Yu, G.S. Cooke, D.C. Schwebel, D.O. Carpenter, D.M. Pereira, D. Nash, D.S. Kazi, D. De Leo, D. Plass, K.N. Ukwaja, G.D. Thurston, K. Yun Jin, E.P. Simard, E. Mills, E.-K. Park, F. Catalá-López, G. deVeber, C. Gotay, G. Khan, H.D. Hosgood, I.S. Santos, J.L. Leasher, J. Singh, J. Leigh, J.B. Jonas, J. Jonas, J. Sanabria, J. Beardsley, K.H. Jacobsen, K. Takahashi, R.C. Franklin, L. Ronfani, M. Montico, L. Naldi, M. Tonelli, J. Geleijnse, M. Petzold, M.G. Shrime, M. Younis, N. Yonemoto, N. Breitborde, P. Yip, F. Pourmalek, P.A. Lotufo, A. Esteghamati, G.J. Hankey, R. Ali, R. Lunevicius, R. Malekzadeh, R. Dellavalle, R. Weintraub, R. Lucas, R. Hay, D. Rojas-Rueda, R. Westerman, S.G. Sepanlou, S. Nolte, S. Patten, S. Weichenthal, S.F. Abera, S.-M. Fereshtehnejad, I. Shiue, T. Driscoll, T. Vasankari, U. Alsharif, V. Rahimi-Movaghar, V. V Vlassov, W.S. Marcenes, W. Mekonnen, Y.A. Melaku, Y. Yano, A. Artaman, I. Campos, J. MacLachlan, U. Mueller, D. Kim, M. Trillini, B. Eshrati, H.C. Williams, K. Shibuya, R. Dandona, K. Murthy, B. Cowie, A.T. Amare, C.A. Antonio, C. Castañeda-Orjuela, C.H. van Gool, F. Violante, I.-H. Oh, K. Deribe, K. Soreide, L. Knibbs, M. Kereselidze, M. Green, R. Cardenas, N. Roy, T. Tillmann, T. Tillman, Y. Li, H. Krueger, L. Monasta, S. Dey, S. Sheikhbahaei, N. Hafezi-Nejad, G.A. Kumar, C.T. Sreeramareddy, L. Dandona, H. Wang, S.E. Vollset, A. Mokdad, J.A. Salomon, R. Lozano, T. Vos, M. Forouzanfar, A. Lopez, C. Murray, M. Naghavi, The Global Burden of Cancer 2013., JAMA Oncol. (2015). doi:10.1001/jamaoncol.2015.0735.

[2] K.E. Lukong, Understanding breast cancer - The long and winding road, BBA Clin. (2017). doi:10.1016/j.bbacli.2017.01.001.

[3] F. Bray, J. Ferlay, I. Soerjomataram, R.L. Siegel, L.A. Torre, A. Jemal, Global cancer statistics 2018: GLOBOCAN estimates of incidence and mortality worldwide for 36 cancers in 185 countries., CA. Cancer J. Clin. (2018). doi:10.3322/caac.21492.

[4] C. Schaal, S.P. Chellappan, Nicotine-Mediated Cell Proliferation and Tumor Progression in Smoking-Related Cancers, Mol. Cancer Res. (2014). doi:10.1158/1541-7786.mcr-130541.

[5] Y. Mao, D. Yang, J. He, M.J. Krasna, Epidemiology of Lung Cancer, Surg. Oncol. Clin. N. Am. (2016). doi:10.1016/j.soc.2016.02.001. 
[6] R.J. Baber, N. Panay, A. Fenton, 2016 IMS Recommendations on womens midlife health and menopause hormone therapy, Climacteric. (2016). doi:10.3109/13697137.2015.1129166.

[7] X.Q. Jiang, X.D. Mei, D. Feng, Air pollution and chronic airway diseases: What should people know and do?, J. Thorac. Dis. (2016). doi:10.3978/j.issn.2072-1439.2015.11.50.

[8] C.-Y. Huang, D.-T. Ju, C.-F. Chang, P. Muralidhar Reddy, B.K. Velmurugan, A review on the effects of current chemotherapy drugs and natural agents in treating non-small cell lung cancer, BioMedicine. (2017). doi:10.1051/bmden/2017070423.

[9] S. Mitrou, D. Petrakis, G. Fotopoulos, G. Zarkavelis, N. Pavlidis, Lung cancer during pregnancy: A narrative review, J. Adv. Res. (2016). doi:10.1016/j.jare.2015.12.004.

[10] J.A. Vendrell, F.T. Mau-Them, B. Béganton, S. Godreuil, P. Coopman, J. Solassol, Circulating cell free tumor DNA detection as a routine tool for lung cancer patient management, Int. J. Mol. Sci. (2017). doi:10.3390/ijms18020264.

[11] J. Ahmad, S. Akhter, M. Rizwanullah, S. Amin, M. Rahman, M.Z. Ahmad, M.A. Rizvi, M.A. Kamal, F.J. Ahmad, Nanotechnology-based inhalation treatments for lung cancer: state of the art., Nanotechnol. Sci. Appl. (2015). doi:10.2147/NSA.S49052.

[12] J.K. Patra, G. Das, L.F. Fraceto, E.V.R. Campos, M. del P. Rodriguez-Torres, L.S. Acosta-Torres, L.A. Diaz-Torres, R. Grillo, M.K. Swamy, S. Sharma, S. Habtemariam, H.-S. Shin, Nano based drug delivery systems: recent developments and future prospects, J. Nanobiotechnology. (2018). doi:10.1186/s12951-018-0392-8.

[13] B. Pelaz, C. Alexiou, R.A. Alvarez-Puebla, F. Alves, A.M. Andrews, S. Ashraf, L.P. Balogh, L. Ballerini, A. Bestetti, C. Brendel, S. Bosi, M. Carril, W.C.W. Chan, C. Chen, X. Chen, X. Chen, Z. Cheng, D. Cui, J. Du, C. Dullin, A. Escudero, N. Feliu, M. Gao, M. George, Y. Gogotsi, A. Grünweller, Z. Gu, N.J. Halas, N. Hampp, R.K. Hartmann, M.C. Hersam, P. Hunziker, J. Jian, X. Jiang, P. Jungebluth, P. Kadhiresan, K. Kataoka, A. Khademhosseini, J. Kopeček, N.A. Kotov, H.F. Krug, D.S. Lee, C.-M. Lehr, K.W. Leong, X.-J. Liang, M. Ling Lim, L.M. Liz-Marzán, X. Ma, P. Macchiarini, H. Meng, H. Möhwald, P. Mulvaney, A.E. Nel, S. Nie, P. Nordlander, T. Okano, J. Oliveira, T.H. Park, R.M. Penner, M. Prato, V. Puntes, V.M. Rotello, A. Samarakoon, R.E. Schaak, Y. Shen, S. Sjöqvist, A.G. Skirtach, M.G. Soliman, M.M. Stevens, H.-W. Sung, B.Z. Tang, R. Tietze, B.N. Udugama, J.S. VanEpps, T. Weil, P.S. Weiss, I. Willner, Y. Wu, L. Yang, Z. 
Yue, Q. Zhang, Q. Zhang, X.-E. Zhang, Y. Zhao, X. Zhou, W.J. Parak, Diverse Applications of Nanomedicine., ACS Nano. (2017). doi:10.1021/acsnano.6b06040.

[14] American Cancer Society, Cancer Facts and Figures 2018 [online], Am. Cancer Soc. (2018).

[15] The Global Cancer Observatory, Lung source: Globocan 2018, Glob. Cancer Obs. (2018).

[16] U.Z. Ikram, J.P. Mackenbach, S. Harding, G. Rey, R.S. Bhopal, E. Regidor, M. Rosato, K. Juel, K. Stronks, A.E. Kunst, All-cause and cause-specific mortality of different migrant populations in Europe, Eur. J. Epidemiol. (2016). doi:10.1007/s10654-015-0083-9.

[17] R.L. Siegel, et al Miller, Cancer Statistics, 2018, Ca Cancer J Clin. (2018). doi:10.3322/caac.21387.

[18] J. Didkowska, U. Wojciechowska, M. Mańczuk, J. Łobaszewski, Lung cancer epidemiology: contemporary and future challenges worldwide, Ann. Transl. Med. (2016). doi:10.21037/atm.2016.03.11.

[19] C. Fitzmaurice, C. Allen, R.M. Barber, L. Barregard, Z.A. Bhutta, H. Brenner, D.J. Dicker, O. Chimed-Orchir, R. Dandona, L. Dandona, T. Fleming, M.H. Forouzanfar, J. Hancock, R.J. Hay, R. Hunter-Merrill, C. Huynh, H.D. Hosgood, C.O. Johnson, J.B. Jonas, J. Khubchandani, G.A. Kumar, M. Kutz, Q. Lan, H.J. Larson, X. Liang, S.S. Lim, A.D. Lopez, M.F. MacIntyre, L. Marczak, N. Marquez, A.H. Mokdad, C. Pinho, F. Pourmalek, J.A. Salomon, J.R. Sanabria, L. Sandar, B. Sartorius, S.M. Schwartz, K.A. Shackelford, K. Shibuya, J. Stanaway, C. Steiner, J. Sun, K. Takahashi, S.E. Vollset, T. Vos, J.A. Wagner, H. Wang, R. Westerman, H. Zeeb, L. Zoeckler, F. Abd-Allah, M.B. Ahmed, S. Alabed, N.K. Alam, S.F. Aldhahri, G. Alem, M.A. Alemayohu, R. Ali, R. AlRaddadi, A. Amare, Y. Amoako, A. Artaman, H. Asayesh, N. Atnafu, A. Awasthi, H.B. Saleem, A. Barac, N. Bedi, I. Bensenor, A. Berhane, E. Bernabé, B. Betsu, A. Binagwaho, D. Boneya, I. Campos-Nonato, C. Castañeda-Orjuela, F. Catalá-López, P. Chiang, C. Chibueze, A. Chitheer, J.Y. Choi, B. Cowie, S. Damtew, J. Das Neves, S. Dey, S. Dharmaratne, P. Dhillon, E. Ding, T. Driscoll, D. Ekwueme, A.Y. Endries, M. Farvid, F. Farzadfar, J. Fernandes, F. Fischer, T.T. Ghiwot, A. Gebru, S. Gopalani, A. Hailu, M. Horino, N. Horita, A. Husseini, I. Huybrechts, M. Inoue, F. Islami, M. Jakovljevic, S. James, M. Javanbakht, S.H. Jee, A. Kasaeian, M.S. Kedir, Y.S. Khader, Y.H. Khang, D. Kim, J. Leigh, S. Linn, R. Lunevicius, H.M.A. El Razek, R. Malekzadeh, D.C. Malta, W. 
Marcenes, D. Markos, Y.A. Melaku, K.G. Meles, W. Mendoza, D.T. Mengiste, T.J. Meretoja, T.R. Miller, K.A. Mohammad, A. Mohammadi, S. Mohammed, M. MoradiLakeh, G. Nagel, D. Nand, Q. Le Nguyen, S. Nolte, F.A. Ogbo, K.E. Oladimeji, E. Oren, M. Pa, E.K. Park, D.M. Pereira, D. Plass, M. Qorbani, A. Radfar, A. Rafay, M. Rahman, S.M. Rana, K. Søreide, M. Satpathy, M. Sawhney, S.G. Sepanlou, M.A. Shaikh, J. She, I. Shiue, H.R. Shore, M.G. Shrime, S. So, S. Soneji, V. Stathopoulou, K. Stroumpoulis, M.B. Sufiyan, B.L. Sykes, R. Tabarés-Seisdedos, F. Tadese, B.A. Tedla, G.A. Tessema, J.S. Thakur, B.X. Tran, K.N. Ukwaja, B.S. Chudi Uzochukwu, V.V. Vlassov, E. Weiderpass, M. Wubshet Terefe, H.G. Yebyo, H.H. Yimam, N. Yonemoto, M.Z. Younis, C. Yu, Z. Zaidi, M.E.S. Zaki, Z.M. Zenebe, C.J.L. Murray, M. Naghavi, Global, regional, and national cancer incidence, mortality, years of life lost, years lived with disability, and disability-adjusted life-years for 32 cancer groups, 1990 to 2015: A Systematic Analysis for the Global Burden of Disease Study Global Burden, JAMA Oncol. (2017). doi:10.1001/jamaoncol.2016.5688.

[20] A.F. Gazdar, P.A. Bunn, J.D. Minna, Small-cell lung cancer: What we know, what we need to know and the path forward, Nat. Rev. Cancer. (2017). doi:10.1038/nrc.2017.87.

[21] M. Hirata, A. Nagai, Y. Kamatani, T. Ninomiya, A. Tamakoshi, Z. Yamagata, M. Kubo, K. Muto, Y. Kiyohara, T. Mushiroda, Y. Murakami, K. Yuji, Y. Furukawa, H. Zembutsu, T. Tanaka, Y. Ohnishi, Y. Nakamura, K. Matsuda, M. Shiono, K. Misumi, R. Kaieda, H. Harada, S. Minami, A. Watanabe, N. Emoto, K. Takahashi, S. Takeda, T. Funaki, S. Asai, M. Moriyama, Y. Takahashi, T. Fujioka, W. Obara, S. Mori, H. Ito, S. Nagayama, Y. Miki, A. Masumoto, A. Yamada, Y. Nishizawa, K. Kodama, H. Kutsumi, Y. Sugimoto, Y. Koretsune, H. Kusuoka, K. Yoshimori, Overview of BioBank Japan follow-up data in 32 diseases, J. Epidemiol. (2017). doi:10.1016/j.je.2016.12.006.

[22] A.J. Farhad Islami, Lindsey A. Torre, Global trends of lung cancer mortality and smoking prevalence, Transl. Lung Cancer Res. (2015). doi:10.3978/j.issn.2218-6751.2015.08.04.

[23] A. McIntyre, A.K. Ganti, Lung cancer-A global perspective, J. Surg. Oncol. (2017). doi:10.1002/jso.24532.

[24] R. Awasthi, M.J. Rathbone, P.M. Hansbro, M. Bebawy, K. Dua, Therapeutic prospects of microRNAs in cancer treatment through nanotechnology, Drug Deliv. Transl. Res. (2018). doi:10.1007/s13346-017-0440-1. 
[25] F. Badrzadeh, M. Rahmati-Yamchi, K. Badrzadeh, A. Valizadeh, N. Zarghami, S.M. Farkhani, A. Akbarzadeh, Drug delivery and nanodetection in lung cancer, Artif. Cells, Nanomedicine Biotechnol. (2016). doi:10.3109/21691401.2014.975237.

[26] J.L. Port, B. Parashar, N. Osakwe, A. Nasar, P.C. Lee, S. Paul, B.M. Stiles, N.K. Altorki, A propensity-matched analysis of wedge resection and stereotactic body radiotherapy for early stage lung cancer, in: Ann. Thorac. Surg., 2014. doi:10.1016/j.athoracsur.2014.04.128.

[27] F.R. Hirsch, K. Suda, J. Wiens, P.A. Bunn, New and emerging targeted treatments in advanced non-small-cell lung cancer, Lancet. (2016). doi:10.1016/S0140-6736(16)314738.

[28] G. Shafirstein, A. Battoo, K. Harris, H. Baumann, S.O. Gollnick, J. Lindenmann, C.E. Nwogu, Photodynamic therapy of non-small cell lung cancer narrative review and future directions, Ann. Am. Thorac. Soc. (2016). doi:10.1513/AnnalsATS.201509-650FR.

[29] M.D. Hellmann, J.E. Chaft, W.N. William, V. Rusch, K.M.W. Pisters, N. Kalhor, A. Pataer, W.D. Travis, S.G. Swisher, M.G. Kris, Pathological response after neoadjuvant chemotherapy in resectable non-small-cell lung cancers: Proposal for the use of major pathological response as a surrogate endpoint, Lancet Oncol. (2014). doi:10.1016/S14702045(13)70334-6.

[30] W.D. Joo, I. Visintin, G. Mor, Targeted cancer therapy - Are the days of systemic chemotherapy numbered?, Maturitas. (2013). doi:10.1016/j.maturitas.2013.09.008.

[31] K. Dua, V. Malyla, G. Singhvi, R. Wadhwa, R.V. Krishna, S.D. Shukla, M.D. Shastri, D.K. Chellappan, P.K. Maurya, S. Satija, M. Mehta, M. Gulati, N. Hansbro, T. Collet, R. Awasthi, G. Gupta, A. Hsu, P.M. Hansbro, Increasing complexity and interactions of oxidative stress in chronic respiratory diseases: An emerging need for novel drug delivery systems, Chem. Biol. Interact. (2019). doi:10.1016/j.cbi.2018.12.009.

[32] F.U. Din, W. Aman, I. Ullah, O.S. Qureshi, O. Mustapha, S. Shafique, A. Zeb, Effective use of nanocarriers as drug delivery systems for the treatment of selected tumors, Int. J. Nanomedicine. (2017). doi:10.2147/IJN.S146315.

[33] V. Agrahari, V. Agrahari, A.K. Mitra, Nanocarrier fabrication and macromolecule drug delivery: challenges and opportunities, Ther. Deliv. (2016). doi:10.4155/tde-2015-0012.

[34] N. Osman, K. Kaneko, V. Carini, I. Saleem, Carriers for the targeted delivery of 
aerosolized macromolecules for pulmonary pathologies, Expert Opin. Drug Deliv. (2018). doi:10.1080/17425247.2018.1502267.

[35] E. Calzoni, A. Cesaretti, A. Polchi, A. Di Michele, B. Tancini, C. Emiliani, Biocompatible Polymer Nanoparticles for Drug Delivery Applications in Cancer and Neurodegenerative Disorder Therapies, J. Funct. Biomater. (2019). doi:10.3390/jfb10010004.

[36] K. Jyoti, K. Kaur, R.S. Pandey, U.K. Jain, R. Chandra, J. Madan, Inhalable nanostructured lipid particles of 9-bromo-noscapine, a tubulin-binding cytotoxic agent: In vitro and in vivo studies, J. Colloid Interface Sci. (2015). doi:10.1016/j.jcis.2014.12.092.

[37] Y. Xin, M. Yin, L. Zhao, F. Meng, L. Luo, Recent progress on nanoparticle-based drug delivery systems for cancer therapy, Cancer Biol. Med. (2017). doi:10.20892/j.issn.20953941.2017.0052.

[38] S.R. Guma, D.A. Lee, Y. Ling, N. Gordon, E.S. Kleinerman, Aerosol interleukin-2 induces natural killer cell proliferation in the lung and combination therapy improves the survival of mice with osteosarcoma lung metastasis, Pediatr. Blood Cancer. (2014). doi:10.1002/pbc.25019.

[39] M. Mehta, Deeksha, N. Sharma, M. Vyas, N. Khurana, P.K. Maurya, H. Singh, T.P. Andreoli de Jesus, H. Dureja, D.K. Chellappan, G. Gupta, R. Wadhwa, T. Collet, P.M. Hansbro, K. Dua, S. Satija, Interactions with the macrophages: An emerging targeted approach using novel drug delivery systems in respiratory diseases, Chem. Biol. Interact. (2019). doi:10.1016/j.cbi.2019.02.021.

[40] W. Gao, C.M.J. Hu, R.H. Fang, L. Zhang, Liposome-like nanostructures for drug delivery, J. Mater. Chem. B. (2013). doi:10.1039/c3tb21238f.

[41] K. Dua, V.K. Rapalli, S.D. Shukla, G. Singhvi, M.D. Shastri, D.K. Chellappan, S. Satija, M. Mehta, M. Gulati, T.D.J.A. Pinto, G. Gupta, P.M. Hansbro, Multi-drug resistant Mycobacterium tuberculosis \& oxidative stress complexity: Emerging need for novel drug delivery approaches, Biomed. Pharmacother. (2018). doi:10.1016/j.biopha.2018.08.101.

[42] M. Çağdaş, A.D. Sezer, S. Bucak, Liposomes as Potential Drug Carrier Systems for Drug Delivery, in: Appl. Nanotechnol. Drug Deliv., 2014. doi:10.5772/58459.

[43] G. Bozzuto, A. Molinari, Liposomes as nanomedical devices, Int. J. Nanomedicine. (2015). doi:10.2147/IJN.S68861.

[44] A. Akbarzadeh, R. Rezaei-Sadabady, S. Davaran, S.W. Joo, N. Zarghami, Y. 
Hanifehpour, M. Samiei, M. Kouhi, K. Nejati-Koshki, Liposome: Classification, preparation, and applications, Nanoscale Res. Lett. (2013). doi:10.1186/1556-276X-8-102.

[45] M.K. Riaz, M.A. Riaz, X. Zhang, C. Lin, K.H. Wong, X. Chen, G. Zhang, A. Lu, Z. Yang, Surface functionalization and targeting strategies of liposomes in solid tumor therapy: A review, Int. J. Mol. Sci. (2018). doi:10.3390/ijms19010195.

[46] L. Sercombe, T. Veerati, F. Moheimani, S.Y. Wu, A.K. Sood, S. Hua, Advances and challenges of liposome assisted drug delivery, Front. Pharmacol. (2015). doi:10.3389/fphar.2015.00286.

[47] H.-Y. Lee, K.A. Mohammed, N. Nasreen, Nanoparticle-based targeted gene therapy for lung cancer., Am. J. Cancer Res. (2016).

[48] J. Chen, Z. Guo, H. Tian, X. Chen, Production and clinical development of nanoparticles for gene delivery, Mol. Ther. - Methods Clin. Dev. (2016). doi:10.1038/mtm.2016.23.

[49] B.S. Pattni, V. V. Chupin, V.P. Torchilin, New Developments in Liposomal Drug Delivery, Chem. Rev. (2015). doi:10.1021/acs.chemrev.5b00046.

[50] D. Lombardo, M.A. Kiselev, M.T. Caccamo, Smart Nanoparticles for Drug Delivery Application: Development of Versatile Nanocarrier Platforms in Biotechnology and Nanomedicine, J. Nanomater. (2019). doi:10.1155/2019/3702518.

[51] J. Madan, K. Dua, P. Khude, Development and evaluation of solid lipid nanoparticles of mometasone furoate for topical delivery, Int. J. Pharm. Investig. (2014). doi:10.4103/2230-973x.133047.

[52] S. Mukherjee, S. Ray, R. Thakur, Solid lipid nanoparticles: A modern formulation approach in drug delivery system, Indian J. Pharm. Sci. (2009). doi:10.4103/0250$474 x .57282$.

[53] M.B. De Jesus, I.S. Zuhorn, Solid lipid nanoparticles as nucleic acid delivery system: Properties and molecular mechanisms, J. Control. Release. (2015). doi:10.1016/j.jconrel.2015.01.010.

[54] J.E.N. Dolatabadi, H. Valizadeh, H. Hamishehkar, Solid lipid nanoparticles as efficient drug and gene delivery systems: Recent breakthroughs, Adv. Pharm. Bull. (2015). doi:10.15171/apb.2015.022.

[55] N. Naseri, H. Valizadeh, P. Zakeri-Milani, Solid lipid nanoparticles and nanostructured lipid carriers: Structure preparation and application, Adv. Pharm. Bull. (2015). 
doi:10.15171/apb.2015.043.

[56] A.J. Almeida, E. Souto, Solid lipid nanoparticles as a drug delivery system for peptides and proteins, Adv. Drug Deliv. Rev. (2007). doi:10.1016/j.addr.2007.04.007.

[57] E. Andreozzi, J.W. Seo, K. Ferrara, A. Louie, Novel method to label solid lipid nanoparticles with $64 \mathrm{Cu}$ for positron emission tomography imaging, Bioconjug. Chem. (2011). doi:10.1021/bc100478k.

[58] P.K. Gaur, S. Mishra, S. Purohit, Solid Lipid Nanoparticles of Guggul Lipid as Drug Carrier for Transdermal Drug Delivery, Biomed Res. Int. (2013). doi:10.1155/2013/750690.

[59] G.M.F. Calixto, J. Bernegossi, L.M. De Freitas, C.R. Fontana, M. Chorilli, A.M. Grumezescu, Nanotechnology-based drug delivery systems for photodynamic therapy of cancer: A review, Molecules. (2016). doi:10.3390/molecules21030342.

[60] E.K. Lim, T. Kim, S. Paik, S. Haam, Y.M. Huh, K. Lee, Nanomaterials for theranostics: Recent advances and future challenges, Chem. Rev. (2015). doi:10.1021/cr300213b.

[61] U.K. Sukumar, B. Bhushan, P. Dubey, I. Matai, A. Sachdev, G. Packirisamy, Emerging applications of nanoparticles for lung cancer diagnosis and therapy, Int. Nano Lett. (2013). doi:10.1186/2228-5326-3-45

[62] S.H. Choi, S.E. Jin, M.K. Lee, S.J. Lim, J.S. Park, B.G. Kim, W.S. Ahn, C.K. Kim, Novel cationic solid lipid nanoparticles enhanced p53 gene transfer to lung cancer cells, Eur. J. Pharm. Biopharm. (2008). doi:10.1016/j.ejpb.2007.07.011.

[63] Y.W. Naguib, B.L. Rodriguez, X. Li, S.D. Hursting, R.O. Williams, Z. Cui, Solid lipid nanoparticle formulations of docetaxel prepared with high melting point triglycerides: In vitro and in vivo evaluation, Mol. Pharm. (2014). doi:10.1021/mp4006968.

[64] S. Khurana, N.K. Jain, P.M.S. Bedi, Development and characterization of a novel controlled release drug delivery system based on nanostructured lipid carriers gel for meloxicam, Life Sci. (2013). doi:10.1016/j.1fs.2013.09.027.

[65] M. Adabi, M. Naghibzadeh, M. Adabi, M.A. Zarrinfard, S.S. Esnaashari, A.M. Seifalian, R. Faridi-Majidi, H. Tanimowo Aiyelabegan, H. Ghanbari, Biocompatibility and nanostructured materials: applications in nanomedicine, Artif. Cells, Nanomedicine Biotechnol. (2017). doi:10.1080/21691401.2016.1178134.

[66] M.H. Akhter, M. Rizwanullah, J. Ahmad, M.J. Ahsan, M.A. Mujtaba, S. Amin, 
Nanocarriers in advanced drug targeting: setting novel paradigm in cancer therapeutics, Artif. Cells, Nanomedicine Biotechnol. (2018). doi:10.1080/21691401.2017.1366333.

[67] Z. Shao, J. Shao, B. Tan, S. Guan, Z. Liu, Z. Zhao, F. He, J. Zhao, Targeted lung cancer therapy: Preparation and optimization of transferrin-decorated nanostructured lipid carriers as novel nanomedicine for co-delivery of anticancer drugs and DNA, Int. J. Nanomedicine. (2015). doi:10.2147/IJN.S77837.

[68] Z.M. Jiang, S.P. Dai, Y.Q. Xu, T. Li, J. Xie, C. Li, Z.H. Zhang, Crizotinib-loaded polymeric nanoparticles in lung cancer chemotherapy, Med. Oncol. (2015). doi:10.1007/s12032-015-0636-5.

[69] D.A. Bolukbas, S. Meiners, Lung cancer nanomedicine: Potentials and pitfalls, Nanomedicine. (2015). doi:10.2217/nnm.15.155.

[70] S. Chen, K. Yang, R.G. Tuguntaev, A. Mozhi, J. Zhang, P.C. Wang, X.J. Liang, Targeting tumor microenvironment with PEG-based amphiphilic nanoparticles to overcome chemoresistance, Nanomedicine Nanotechnology, Biol. Med. (2016). doi:10.1016/j.nano.2015.10.020.

[71] H. Kharkwal, K. Bala, D.P. Katare, Biodegradable Polymers, Role in Enhancing Bioavailability of Drug, 2011.

[72] S. Maiolino, A. Russo, V. Pagliara, C. Conte, F. Ungaro, G. Russo, F. Quaglia, Biodegradable nanoparticles sequentially decorated with Polyethyleneimine and Hyaluronan for the targeted delivery of docetaxel to airway cancer cells, J. Nanobiotechnology. (2015). doi:10.1186/s12951-015-0088-2.

[73] L. Jiang, L. Li, X. He, Q. Yi, B. He, J. Cao, W. Pan, Z. Gu, Overcoming drug-resistant lung cancer by paclitaxel loaded dual-functional liposomes with mitochondria targeting and pH-response, Biomaterials. (2015). doi:10.1016/j.biomaterials.2015.02.004.

[74] C. Boyer, J. Teo, P. Phillips, R.B. Erlich, S. Sagnella, G. Sharbeen, T. Dwarte, H.T.T. Duong, D. Goldstein, T.P. Davis, M. Kavallaris, J. McCarroll, Effective delivery of siRNA into cancer cells and tumors using well-defined biodegradable cationic star polymers, Mol. Pharm. (2013). doi:10.1021/mp400049e.

[75] J.E. Dahlman, C. Barnes, O.F. Khan, A. Thiriot, S. Jhunjunwala, T.E. Shaw, Y. Xing, H.B. Sager, G. Sahay, L. Speciner, A. Bader, R.L. Bogorad, H. Yin, T. Racie, Y. Dong, S. Jiang, D. Seedorf, A. Dave, K. Singh Sandhu, M.J. Webber, T. Novobrantseva, V.M. 
Ruda, A.K.R. Lytton-Jean, C.G. Levins, B. Kalish, D.K. Mudge, M. Perez, L. Abezgauz, P. Dutta, L. Smith, K. Charisse, M.W. Kieran, K. Fitzgerald, M. Nahrendorf, D. Danino, R.M. Tuder, U.H. Von Andrian, A. Akinc, D. Panigrahy, A. Schroeder, V. Koteliansky, R. Langer, D.G. Anderson, In vivo endothelial siRNA delivery using polymeric nanoparticles with low molecular weight, Nat. Nanotechnol. (2014). doi:10.1038/nnano.2014.84.

[76] W. Xu, P. Ling, T. Zhang, Polymeric Micelles, a Promising Drug Delivery System to Enhance Bioavailability of Poorly Water-Soluble Drugs, J. Drug Deliv. (2013). doi:10.1155/2013/340315.

[77] X. Qu, Y. Zou, C. He, Y. Zhou, Y. Jin, Y. Deng, Z. Wang, X. Li, Y. Zhou, Y. Liu, Improved intestinal absorption of paclitaxel by mixed micelles self-assembled from vitamin E succinate-based amphiphilic polymers and their transcellular transport mechanism and intracellular trafficking routes, Drug Deliv. (2018). doi:10.1080/10717544.2017.1419513.

[78] Y. Gao, Y. Zhou, L. Zhao, C. Zhang, Y. Li, J. Li, X. Li, Y. Liu, Enhanced antitumor efficacy by cyclic RGDyK-conjugated and paclitaxel-loaded $\mathrm{pH}$-responsive polymeric micelles, Acta Biomater. (2015). doi:10.1016/j.actbio.2015.05.021.

[79] L. Zhang, Z. Liu, C. Kong, C. Liu, K. Yang, H. Chen, J. Huang, F. Qian, Improving Drug Delivery of Micellar Paclitaxel against Non-Small Cell Lung Cancer by Coloading Itraconazole as a Micelle Stabilizer and a Tumor Vascular Manipulator, Small. (2018). doi:10.1002/smll.201802112.

[80] D. Mei, L. Zhao, B. Chen, X. Zhang, X. Wang, Z. Yu, X. Ni, Q. Zhang, $\alpha$-Conotoxin imimodified polymeric micelles as potential nanocarriers for targeted docetaxel delivery to $\alpha 7-n A C h R$ overexpressed non-small cell lung cancer, Drug Deliv. (2018). doi:10.1080/10717544.2018.1436097.

[81] D. Pandita, N. Poonia, S. Kumar, V. Lather, K. Madaan, Dendrimers in drug delivery and targeting: Drug-dendrimer interactions and toxicity issues, J. Pharm. Bioallied Sci. (2014). doi:10.4103/0975-7406.130965.

[82] D. Lombardo, Modeling Dendrimers Charge Interaction in Solution: Relevance in Biosystems, Biochem. Res. Int. (2014). doi:10.1155/2014/837651.

[83] M. Kalomiraki, K. Thermos, N.A. Chaniotakis, Dendrimers as tunable vectors of drug delivery systems and biomedical and ocular applications, Int. J. Nanomedicine. (2015). 
doi:10.2147/IJN.S93069.

[84] S. Mignani, J.P. Majoral, Dendrimers as macromolecular tools to tackle from colon to brain tumor types: A concise overview, New J. Chem. (2013). doi:10.1039/c3nj00300k.

[85] P. SZYMAŃSKI, M. MARKOWICZ, E. MIKICIUK-OLASIK, NANOTECHNOLOGY IN PHARMACEUTICAL AND BIOMEDICAL APPLICATIONS: DENDRIMERS, Nano. (2011). doi:10.1142/s1793292011002871.

[86] J. Liu, J. Liu, L. Chu, Y. Wang, Y. Duan, L. Feng, C. Yang, L. Wang, D. Kong, Novel peptide-dendrimer conjugates as drug carriers for targeting nonsmall cell lung cancer, Int. J. Nanomedicine. (2011). doi:10.2147/IJN.S14601.

[87] S. Somani, P. Laskar, N. Altwaijry, P. Kewcharoenvong, C. Irving, G. Robb, B.S. Pickard, C. Dufès, PEGylation of polypropylenimine dendrimers: Effects on cytotoxicity, DNA condensation, gene delivery and expression in cancer cells, Sci. Rep. (2018). doi:10.1038/s41598-018-27400-6.

[88] G. Bao, S. Mitragotri, S. Tong, Multifunctional Nanoparticles for Drug Delivery and Molecular Imaging, Annu. Rev. Biomed. Eng. (2013). doi:10.1146/annurev-bioeng071812-152409.

[89] A. Akbarzadeh, M. Samiei, S. Davaran, Magnetic nanoparticles: Preparation, physical properties, and applications in biomedicine, Nanoscale Res. Lett. (2012). doi:10.1186/1556-276X-7-144.

[90] T.D. Schladt, K. Schneider, H. Schild, W. Tremel, Synthesis and bio-functionalization of magnetic nanoparticles for medical diagnosis and treatment, Dalt. Trans. (2011). doi:10.1039/c0dt00689k.

[91] R.A. Revia, M. Zhang, Magnetite nanoparticles for cancer diagnosis, treatment, and treatment monitoring: Recent advances, Mater. Today. (2016). doi:10.1016/j.mattod.2015.08.022.

[92] B. Issa, I.M. Obaidat, B.A. Albiss, Y. Haik, Magnetic nanoparticles: Surface effects and properties related to biomedicine applications, Int. J. Mol. Sci. (2013). doi:10.3390/ijms141121266.

[93] W. Wu, Z. Wu, T. Yu, C. Jiang, W.S. Kim, Recent progress on magnetic iron oxide nanoparticles: Synthesis, surface functional strategies and biomedical applications, Sci. Technol. Adv. Mater. (2015). doi:10.1088/1468-6996/16/2/023501. 
[94] S. Laurent, M. Mahmoudi, Superparamagnetic iron oxide nanoparticles: Promises for diagnosis and treatment of cancer, Int. J. Mol. Epidemiol. Genet. (2011).

[95] B. Gaihre, M.S. Khil, H.Y. Kim, In vitro anticancer activity of doxorubicin-loaded gelatin-coated magnetic iron oxide nanoparticles, J. Microencapsul. (2011). doi:10.3109/02652048.2011.559286.

[96] K. Nejati-Koshki, M. Mesgari, E. Ebrahimi, F. Abbasalizadeh, S.F. Aval, A.A. Khandaghi, M. Abasi, A. Akbarzadeh, Synthesis and in vitro study of cisplatin-loaded $\mathrm{Fe}<$ inf $>3</$ inf $>\mathrm{O}<$ inf $>4</$ inf $>$ nanoparticles modified with $\mathrm{PLGA}-\mathrm{PEG}<$ inf $>6000</$ inf $>$ copolymers in treatment of lung cancer, J. Microencapsul. (2014). doi:10.3109/02652048.2014.940011.

[97] V. Orel, A. Shevchenko, A. Romanov, M. Tselepi, T. Mitrelias, C.H.W. Barnes, A. Burlaka, S. Lukin, I. Shchepotin, Magnetic properties and antitumor effect of nanocomplexes of iron oxide and doxorubicin, Nanomedicine Nanotechnology, Biol. Med. (2015). doi:10.1016/j.nano.2014.07.007.

[98] L. Sadeghi, V. Yousefi Babadi, H.R. Espanani, Toxic effects of the Fe2O3 nanoparticles on the liver and lung tissue., Bratisl. Lek. Listy. (2015).

[99] L.B. Laurentius, N.A. Owens, J. Park, A.C. Crawford, M.D. Porter, Advantages and limitations of nanoparticle labeling for early diagnosis of infection, Expert Rev. Mol. Diagn. (2016). doi:10.1080/14737159.2016.1205489.

[100] J. Kudr, Y. Haddad, L. Richtera, Z. Heger, M. Cernak, V. Adam, O. Zitka, Magnetic Nanoparticles: From Design and Synthesis to Real World Applications, Nanomaterials. (2017). doi:10.3390/nano7090243.

[101] Z.W. Tay, P. Chandrasekharan, X.Y. Zhou, E. Yu, B. Zheng, S. Conolly, In vivo tracking and quantification of inhaled aerosol using magnetic particle imaging towards inhaled therapeutic monitoring, Theranostics. (2018). doi:10.7150/thno.26608.

[102] M. Rogosnitzky, S. Branch, Gadolinium-based contrast agent toxicity: a review of known and proposed mechanisms, BioMetals. (2016). doi:10.1007/s10534-016-9931-7.

[103] S. Kuroda, J. Tam, J.A. Roth, K. Sokolov, R. Ramesh, EGFR-targeted plasmonic magnetic nanoparticles suppress lung tumor growth by abrogating G2/M cell-cycle arrest and inducing DNA damage, Int. J. Nanomedicine. (2014). doi:10.2147/IJN.S65990.

[104] T. Yokoyama, J. Tam, S. Kuroda, A.W. Scott, J. Aaron, T. Larson, M. Shanker, A.M. 
Correa, S. Kondo, J.A. Roth, K. Sokolov, R. Ramesh, Egfr-targeted hybrid plasmonic magnetic nanoparticles synergistically induce autophagy and apoptosis in non-small cell lung cancer cells, PLoS One. (2011). doi:10.1371/journal.pone.0025507.

[105] R. Iyer, C.C.W. Hsia, K.T. Nguyen, Nano-Therapeutics for the Lung: State-of-the-Art and Future Perspectives., Curr. Pharm. Des. (2015).

[106] N.A. Stocke, S.A. Meenach, S.M. Arnold, H.M. Mansour, J.Z. Hilt, Formulation and characterization of inhalable magnetic nanocomposite microparticles (MnMs) for targeted pulmonary delivery via spray drying, Int. J. Pharm. (2015). doi:10.1016/j.ijpharm.2014.12.050.

[107] Y. Liu, P. Zhang, F. Li, X. Jin, J. Li, W. Chen, Q. Li, Metal-based NanoEnhancers for future radiotherapy: Radiosensitizing and synergistic effects on tumor cells, Theranostics. (2018). doi:10.7150/thno.22172.

[108] N. Saifuddin, A.Z. Raziah, A.R. Junizah, Carbon nanotubes: A review on structure and their interaction with proteins, J. Chem. (2013). doi:10.1155/2013/676815.

[109] H.C. Wu, X. Chang, L. Liu, F. Zhao, Y. Zhao, Chemistry of carbon nanotubes in biomedical applications, J. Mater. Chem. (2010). doi:10.1039/b911099m.

[110] X. Li, L. Wang, Y. Fan, Q. Feng, F. Cui, Biocompatibility and Toxicity of Nanoparticles and Nanotubes, J. Nanomater. (2012). doi:10.1155/2012/548389.

[111] A. Kausar, I. Rafique, B. Muhammad, Review of Applications of Polymer/Carbon Nanotubes and Epoxy/CNT Composites, Polym. - Plast. Technol. Eng. (2016). doi:10.1080/03602559.2016.1163588.

[112] A.A. Bhirde, V. Patel, J. Gavard, G. Zhang, A.A. Sousa, A. Masedunskas, R.D. Leapman, R. Weigert, J.S. Gutkind, J.F. Rusling, Targeted killing of cancer cells in vivo and in vitro with EGF-directed carbon nanotube-based drug delivery, ACS Nano. (2009). doi:10.1021/nn800551s.

[113] V. Rastogi, P. Yadav, S.S. Bhattacharya, A.K. Mishra, N. Verma, A. Verma, J.K. Pandit, Carbon Nanotubes: An Emerging Drug Carrier for Targeting Cancer Cells, J. Drug Deliv. (2014). doi:10.1155/2014/670815.

[114] L. Wang, M. Zhang, N. Zhang, J. Shi, H. Zhang, M. Li, C. Lu, Z. Zhang, Synergistic enhancement of cancer therapy using a combination of docetaxel and photothermal ablation induced by single-walled carbon nanotubes., Int. J. Nanomedicine. (2011). 
[115] G. Ciofani, V. Raffa, V. Pensabene, A. Menciassi, P. Dario, Dispersion of multi-walled carbon nanotubes in aqueous pluronic F127 solutions for biological applications, Fullerenes Nanotub. Carbon Nanostructures. (2009). doi:10.1080/15363830802515840.

[116] H. Ali-Boucetta, K.T. Al-Jamal, D. McCarthy, M. Prato, A. Bianco, K. Kostarelos, Multiwalled carbon nanotube-doxorubicin supramolecular complexes for cancer therapeutics, Chem. Commun. (2002). doi:10.1039/b712350g.

[117] F.P. Milton, J. Govan, M. V. Mukhina, Y.K. Gun'Ko, The chiral nano-world: Chiroptically active quantum nanostructures, Nanoscale Horizons. (2016). doi:10.1039/c5nh00072f.

[118] A.B. Chinen, C.M. Guan, J.R. Ferrer, S.N. Barnaby, T.J. Merkel, C.A. Mirkin, Nanoparticle Probes for the Detection of Cancer Biomarkers, Cells, and Tissues by Fluorescence, Chem. Rev. (2015). doi:10.1021/acs.chemrev.5b00321.

[119] P. Zrazhevskiy, M. Sena, X. Gao, Designing multifunctional quantum dots for bioimaging, detection, and drug delivery, Chem. Soc. Rev. (2010). doi:10.1039/b915139g.

[120] S.J. Rosenthal, J.C. Chang, O. Kovtun, J.R. McBride, I.D. Tomlinson, Biocompatible quantum dots for biological applications, Chem. Biol. (2011). doi:10.1016/j.chembiol.2010.11.013.

[121] N. Lewinski, V. Colvin, R. Drezek, Cytotoxicity of nanopartides, Small. (2008). doi:10.1002/smll.200700595.

[122] L. Hu, C. Zhang, G. Zeng, G. Chen, J. Wan, Z. Guo, H. Wu, Z. Yu, Y. Zhou, J. Liu, Metal-based quantum dots: Synthesis, surface modification, transport and fate in aquatic environments and toxicity to microorganisms, RSC Adv. (2016). doi:10.1039/c6ra13016j.

[123] M.L. Schipper, Z. Cheng, S.-W. Lee, L.A. Bentolila, G. Iyer, J. Rao, X. Chen, A.M. Wu, S. Weiss, S.S. Gambhir, microPET-Based Biodistribution of Quantum Dots in Living Mice, J. Nucl. Med. (2007). doi:10.2967/jnumed.107.040071.

[124] Y.G. Qu, Q. Zhang, Q. Pan, X. Da Zhao, Y.H. Huang, F.C. Chen, H.L. Chen, Quantum dots immunofluorescence histochemical detection of EGFR gene mutations in the nonsmall cell lung cancers using mutation-specific antibodies, Int. J. Nanomedicine. (2014). doi:10.2147/IJN.S71310.

[125] J. Zhou, Y. Liu, J. Tang, W. Tang, Surface ligands engineering of semiconductor quantum dots for chemosensory and biological applications, Mater. Today. (2017). 
doi:10.1016/j.mattod.2017.02.006.

[126] R. Luigetti, P. Bachmann, E. Cooke, T. Salmonson, Collaboration, not competition: developing new reliance models, WHO Drug Inf. (2016).

[127] A.C. Anselmo, S. Mitragotri, Nanoparticles in the clinic, Bioeng. Transl. Med. (2016). doi:10.1002/btm2.10003.

[128] H.K. Ahn, M. Jung, S.J. Sym, D.B. Shin, S.M. Kang, S.Y. Kyung, J.W. Park, S.H. Jeong, E.K. Cho, A phase II trial of Cremorphor EL-free paclitaxel (Genexol-PM) and gemcitabine in patients with advanced non-small cell lung cancer, Cancer Chemother. Pharmacol. (2014). doi:10.1007/s00280-014-2498-5.

[129] Liposomal SN-38 in Treating Patients With Small Cell Lung Cancer - Full Text View ClinicalTrials.gov, (n.d.). https://clinicaltrials.gov/ct2/show/NCT00104754?term=liposomes\&cond=Lung+Cancer\& rank=1 (accessed May 27, 2019).

[130] Study of Irinotecan Liposome Injection (ONIVYDE®) in Patients With Small Cell Lung Cancer - Full Text View - ClinicalTrials.gov, (n.d.).

https://clinicaltrials.gov/ct2/show/NCT03088813?term=liposomes\&cond=Lung+Cancer\& rank=2 (accessed May 27, 2019).

[131] A Study of BIND-014 (Docetaxel Nanoparticles for Injectable Suspension) as Second-line Therapy for Patients With KRAS Positive or Squamous Cell Non-Small Cell Lung Cancer - Full Text View - ClinicalTrials.gov, (n.d.). https://clinicaltrials.gov/ct2/show/NCT02283320?term=nanoparticles\&cond=Lung+Cance r\&rank=2 (accessed May 27, 2019).

[132] Paclitaxel Albumin-Stabilized Nanoparticle Formulation and Sunitinib as First-Line Therapy in Treating Patients With Stage IV Non-Small Cell Lung Cancer - Full Text View - ClinicalTrials.gov, (n.d.). https://clinicaltrials.gov/ct2/show/NCT00748163?term=nanoparticles\&cond=Lung+Cance r\&rank=3 (accessed May 27, 2019).

[133] TUSC2-nanoparticles and Erlotinib in Stage IV Lung Cancer - Full Text View ClinicalTrials.gov, (n.d.). https://clinicaltrials.gov/ct2/show/NCT01455389?term=nanoparticles\&cond=Lung+Cance r\&rank=6 (accessed May 27, 2019). 
[134] A Trial of Paclitaxel (Genexol®) and Cisplatin Versus Paclitaxel Loaded Polymeric Micelle (Genexol-PM®) and Cisplatin in Advanced Non Small Cell Lung Cancer - Full Text View - ClinicalTrials.gov, (n.d.).

https://clinicaltrials.gov/ct2/show/NCT01023347?term=micelles\&cond=Lung+Cancer\&ra nk=1 (accessed May 27, 2019). 
Table 1. Applications of different types of nanoparticles [25]

\begin{tabular}{lllllll}
\hline Types of nanoparticles & \multicolumn{9}{c}{ Application of nanoparticles } & & \\
& DD & GT & IM & MRI & PDT & PTT \\
\hline Carbon Nanotubes & $\sqrt{ }$ & $\sqrt{ }$ & & & $\sqrt{ }$ & \\
Dendrimers & & & $\sqrt{ }$ & & & \\
Gold Nanoparticles & $\sqrt{ }$ & $\sqrt{ }$ & & & $\sqrt{ }$ & $\sqrt{ }$ \\
Liposomes & $\sqrt{ }$ & & $\sqrt{ }$ & & & \\
Magnetic Nanoparticles & $\sqrt{ }$ & & & $\sqrt{ }$ & \\
Polymeric micelles & $\sqrt{ }$ & & $\sqrt{ }$ & & \\
Quantum dots & $\sqrt{ }$ & & $\sqrt{ }$ & & \\
\hline
\end{tabular}

DD- Drug Delivery; GT- Gene therapy; IM- Imaging; MRI- Magnetic Resonance Imaging; PDTPhotodynamic Therapy; PPT- Photothermal Therapy

Table 2. Advantages and disadvantages of different types of magnetic nanoparticles

\begin{tabular}{|c|c|c|c|}
\hline Type & Advantages & Disadvantages & References \\
\hline $\begin{array}{l}\text { Co-polymer } \\
\text { modified } \\
\text { magnetic } \\
\text { nanoparticles }\end{array}$ & $\begin{array}{l}\text { - Suitable carrier for } \\
\text { a hydrophobic } \\
\text { therapeutic agent }\end{array}$ & $\begin{array}{l}\text { Non-specific } \\
\text { targeting }\end{array}$ & [96] \\
\hline $\begin{array}{l}\text { Iron oxide } \\
\text { nanoparticles }\end{array}$ & $\begin{array}{l}\text { - Biocompatible } \\
\text { - Biodegradable }\end{array}$ & $\begin{array}{l}\text { - Cause toxicity } \\
\text { due to ROS } \\
\text { production } \\
\text { - Non-specific } \\
\text { targeting }\end{array}$ & {$[97][98]$} \\
\hline $\begin{array}{l}\text { Gold } \\
\text { magnetic } \\
\text { nanoparticles }\end{array}$ & $\begin{array}{l}\text { - Safe } \\
\text { - Enhanced } \\
\text { bioavailability } \\
\text { - Accumulate at } \\
\text { tumor site and } \\
\text { enhance x-ray } \\
\text { effect }\end{array}$ & $\begin{array}{l}\text { - Stability } \\
\text { related issue } \\
\text { during aqueous } \\
\text { formulation }\end{array}$ & [99] \\
\hline $\begin{array}{l}\text { Silver } \\
\text { magnetic } \\
\text { nanoparticles }\end{array}$ & $\begin{array}{l}\text { - Induce apoptosis in } \\
\text { the targeted area } \\
\text { - Accumulate at the } \\
\text { tumor site and } \\
\text { enhance x-ray } \\
\text { effect }\end{array}$ & $\begin{array}{l}\text { - Cause toxicity } \\
\text { due to ROS } \\
\text { production }\end{array}$ & {$[100]$} \\
\hline Aerosol & - Stable & - Early release of & [101] \\
\hline
\end{tabular}




\begin{tabular}{llll}
\hline $\begin{array}{l}\text { based } \\
\text { magnetic } \\
\text { nanoparticles }\end{array}$ & $\begin{array}{l}\text { Prevent systemic } \\
\text { targeting as drug } \\
\text { deposits in lungs }\end{array}$ & $\begin{array}{l}\text { drug in upper } \\
\text { respiratory tract } \\
\text { Less availability } \\
\text { of drug at target } \\
\text { site }\end{array}$ \\
Goldolinium & - Stable & - Renal failure in \\
magnetic & - Safe & NFD \\
nanoparticles & - Prevent systemic & (Nephrogenic \\
& toxicity & fibrosing \\
& & dermopathy) \\
& & patients \\
\hline
\end{tabular}

Table 3. List of clinical trials on nanoparticle based formulations for lung cancers

\begin{tabular}{|c|c|c|c|c|}
\hline Drug & Carrier & $\begin{array}{l}\text { Development } \\
\text { stage }\end{array}$ & Objectives of study & Reference \\
\hline Liposomal SN-38 & Liposomes & Phase -II & $\begin{array}{l}\text { To stop the growth of tumor } \\
\text { cells, either by killing the } \\
\text { cells or by stopping them } \\
\text { from dividing }\end{array}$ & [129] \\
\hline $\begin{array}{l}\text { Irinotecan, } \\
\text { Topotecan }\end{array}$ & Liposomes & Phase -II & $\begin{array}{l}\text { To determine the dose of } \\
\text { Irinotecan injection } \\
\text { To study the efficacy of } \\
\text { irinotecan injection versus } \\
\text { topotecan }\end{array}$ & [130] \\
\hline $\begin{array}{l}\text { BIND-014 } \\
\text { (Docetaxel } \\
\text { nanoparticles for } \\
\text { Injectable } \\
\text { Suspension) }\end{array}$ & Nanoparticles & & $\begin{array}{l}\text { To study the effect of } \\
\text { docetaxel nanoparticle } \\
\text { injection in patients with } \\
\text { squamous cell non-small cell } \\
\text { lung cancer (NSCLC) who } \\
\text { have progressed after } \\
\text { treatment of one prior } \\
\text { platinum-containing } \\
\text { chemotherapy regimen }\end{array}$ & [131] \\
\hline $\begin{array}{l}\text { Paclitaxel } \\
\text { albumin- } \\
\text { stabilized } \\
\text { nanoparticle, } \\
\text { Sunitinib malate }\end{array}$ & Nanoparticles & Phase-II & $\begin{array}{l}\text { To study the combination } \\
\text { effect of paclitaxel albumin- } \\
\text { stabilized nanoparticle } \\
\text { formulation along with } \\
\text { sunitinib to kill tumor cells }\end{array}$ & [132] \\
\hline $\begin{array}{l}\text { DOTAP:Chol- } \\
\text { TUSC2, } \\
\text { Erlotinib }\end{array}$ & Nanoparticles & Phase-I & $\begin{array}{l}\text { To find the highest dose of } \\
\text { DOTAP:Chol-TUSC2 that } \\
\text { can be safely given in } \\
\text { combination with Tarceva } \\
\text { (erlotinib hydrochloride) to } \\
\text { patients with NSCLC. }\end{array}$ & [133] \\
\hline
\end{tabular}




\begin{tabular}{lll}
\hline Paclitaxel, & Polymeric & To compare the efficacy of [134] \\
Paclitaxel loaded & micelles & Paclitaxel and Cisplatin \\
polymeric & & versus Paclitaxel loaded \\
micelles & polymeric micelles and \\
& Cisplatin in advanced non \\
& small cell lung cancer \\
\hline
\end{tabular}




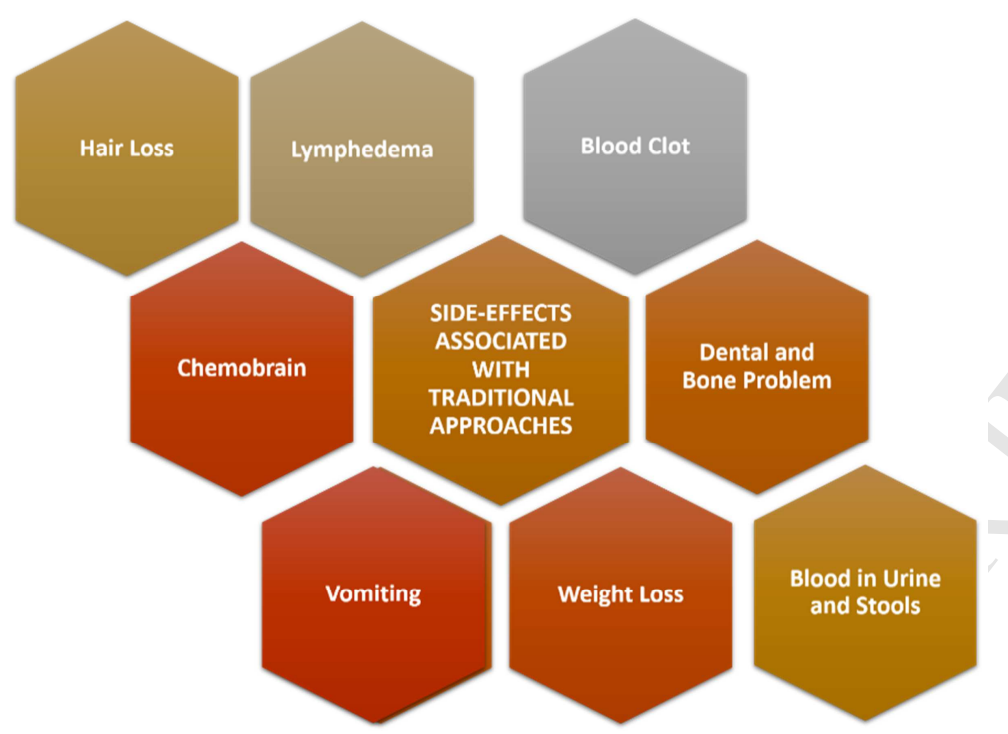

Fig. 1. General diagrammatic representation of side-effects associated with traditional

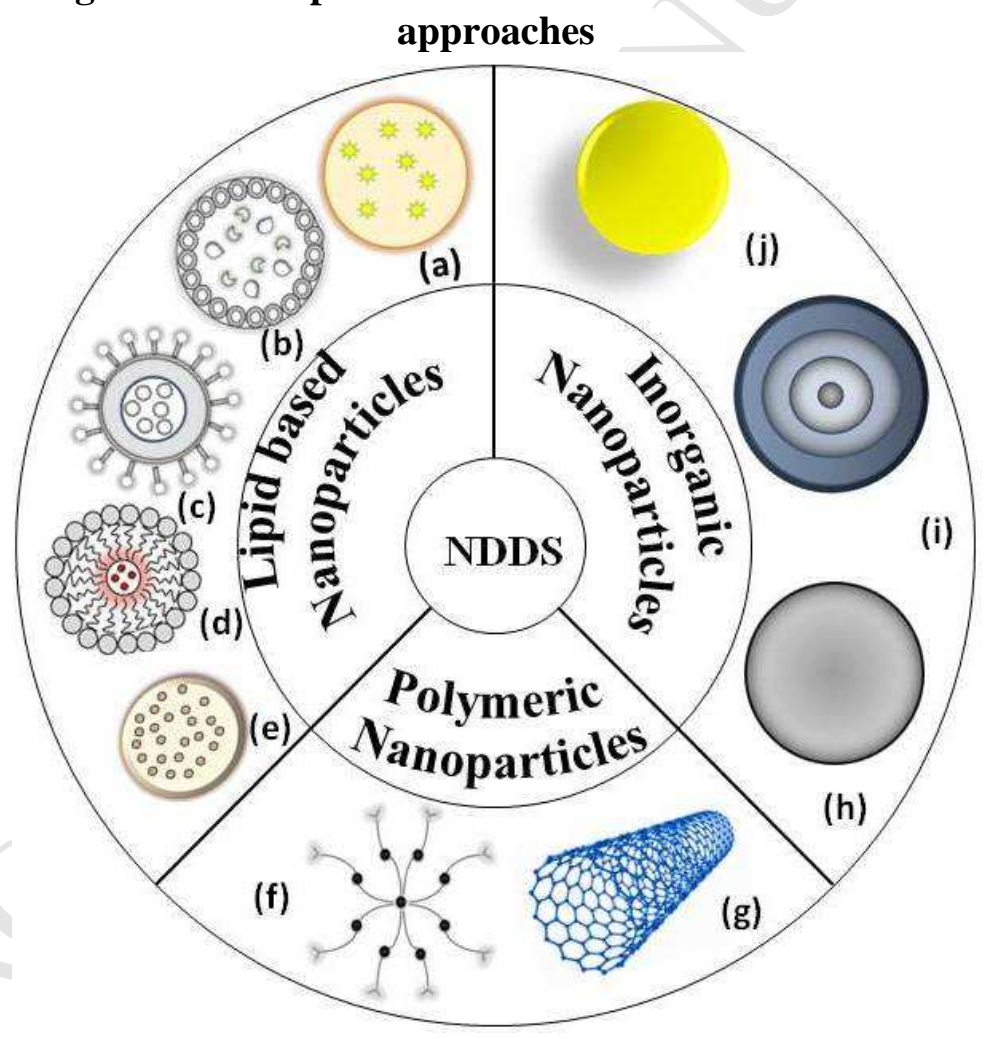

Fig. 2. Systematic representation of different novel drug delivery system i.e. (a) Nanostructured lipid carrier (b) Solid lipid nanoparticles (c) Liposomes (d) Lipid micelle (e) Nanostructured lipid emulsion (f) dendrimers (g) Carbon nanotube (h) Iron oxide nanoparticles (i) Quantum dot (j) Gold nanoparticles 


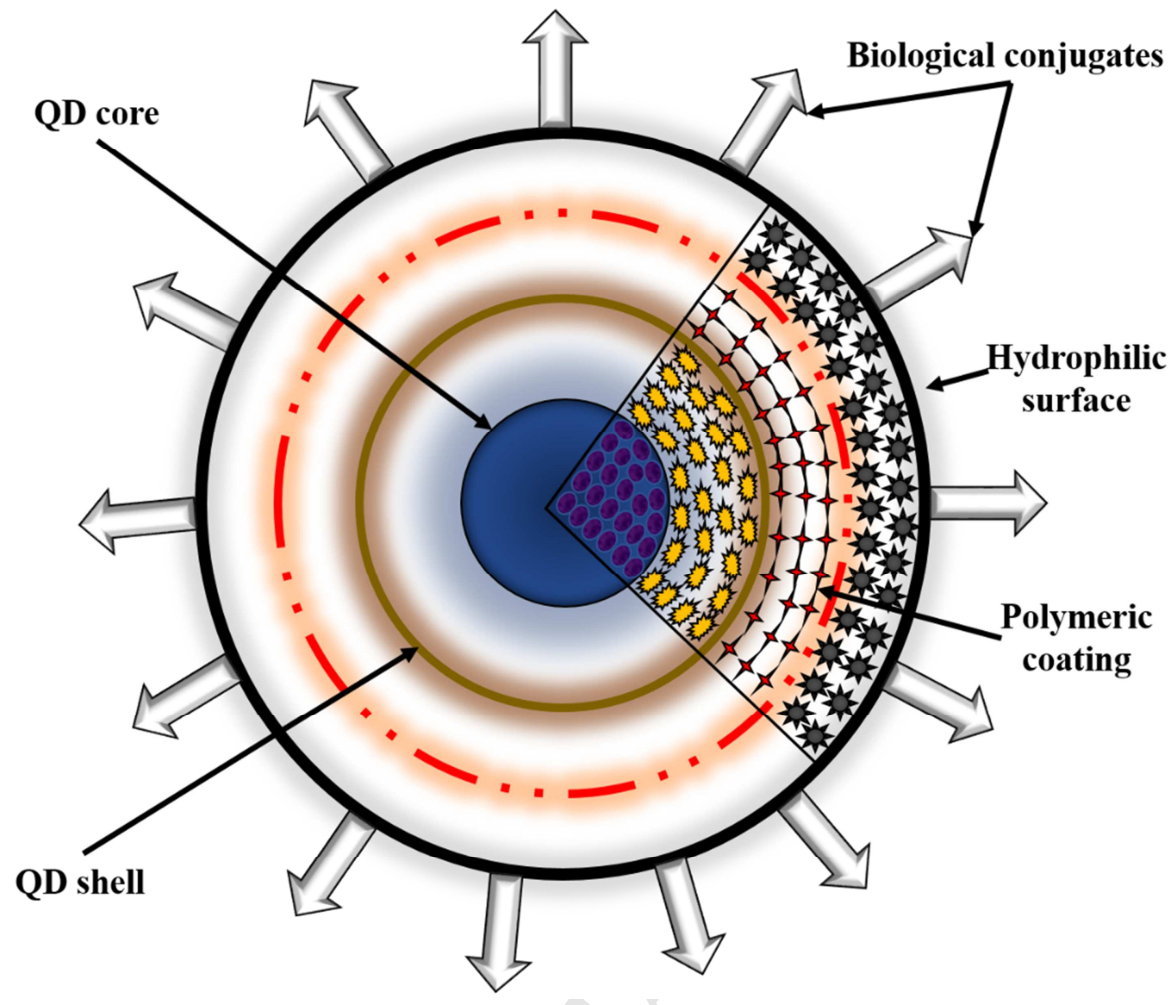

Fig. 3. General structure and cross-sectional view of quantum dots 


\section{Highlights}

- Lung cancer is one of the most prevalent form of cancer worldwide.

- Traditional treatment methods includes surgery, radiation and chemotherapy.

- Main side effects of existing treatments are nonspecific targeting and toxicity.

- Novel drug delivery offers improved bioavailability and site-specific targeting.

- Emerging trends in drug delivery will provide new direction to lung cancer clinics. 


\section{Declaration of interests}

$\bigotimes$ The authors declare that they have no known competing financial interests or personal relationships that could have appeared to influence the work reported in this paper.

$\square$ The authors declare the following financial interests/personal relationships which may be considered as potential competing interests: 